\title{
Fashion Design from Woven Fabrics of Community Enterprise Group
}

\author{
Nirat Soodsang ${ }^{1}$ \\ ${ }^{1}$ Faculty of Architecture, Department of Art and Design, Naresuan University, Thailand \\ Correspondence: Nirat Soodsang, Faculty of Architecture, Naresuan University, Phitsanulok 65000, Thailand. \\ Tel: 66-83-96-2450. E-mail: nirats@nu.ac.th
}

Received: October 3, 2015 Accepted: January 18, 2016 Online Published: February 23, 2016

doi:10.5539/ass.v12n3p31

URL: http://dx.doi.org/10.5539/ass.v12n3p31

\begin{abstract}
The objectives of this study were to 1) design fashion and bags from woven fabrics of the community enterprise group in Pitsanulok province 2) compare the quality of products based on the criteria used to measure community products classified by features, genders, level of income and 3) present a prototype from local woven fabrics in Pitsanulok province. The research procedure includes the sample group which incorporates 67 consumers in their working ages. Accidental sampling design was implemented. The instruments were modified and validated by the standard of community products scp. 196/2003 entitled handmade products from fabrics quality assured in terms of the product neatness, benefits, materials, and manufacturing processes as well as marketing possibility and career advancement. The results were that the fashion design and bags from the local woven fabrics proposed as the prototype had their own valued adding and could be able to market. As regards the quality assurance, the satisfactory level was good. Also, when the satisfactory level of the consumers towards the products were compared regarding genders and level of income, there was no significant differences found.
\end{abstract}

Keywords: fashion design, woven fabric, Pitsanulok province

\section{Introduction}

Fashion Design from Woven Fabrics of Community Enterprise Group in Phitsanulok Province, Thailand is one of the government policies to promote and support the market of the community products. The products include clothes, home decoration products, gifts, and souvenirs. These promotion and products target both Thai and foreign markets. The products represent the uniqueness of Thai culture. The products themselves also tell a story of the traditional Thai ways of living. Arising from the government policy to tackle the poverty in the rural areas, the government initiated the one tamboon one product project which is known as OTOP project. The project was developed on the basis to increase the income for the house wholes and to elevate the standard of living of the people in the rural communities. The project has also emphasized the local uniqueness which embraces the production and management.The products are to present their indigenous ways of life and primitive cultures. Another aspect to put into consideration is how to add the value to the products. The value does not only refer to the income but also include local wisdom, culture, skills, nature of the community, peacefulness, ways of life, natural materials, crops, and many more. These are considered foundation or societal capital of the community. As a consequence, what we need to do is to strengthen our existing knowledge and to upgrade our products by applying technology and advance knowledge for the sustainability.

Pitsanulok province has a reputation for its woven fabrics. There are many techniques applied in weaving fabrics namely loomed textile in flower pattern; silk woven with the northeastern Thailand style in Tasakea subdistrict; basic handmade silk woven of Padang subdistrict in Chatikarn district; handmade cotton woven fabrics of Namprik Village; percussion loomed woven fabrics; synthetic silk woven fabrics; and lastly ikat woven fabrics of Nakron Thai district. Moreover, there have also been fabrics from synthetic silk or cotton patterned and dyed as designed of Neun Maprang district; colorful handmade synthetic silk interwoven with ikat of Wang Thong district.

In this study, the researcher conducted an in-depth study of the Thai woven community enterprise group at Ban Krang Taa Wau in Muang District of Phitsanulok Province, Thailand. This village was selected in this study because of their potentiality in supplying raw materials to the production process. The researcher, therefore, came up with an idea to design local woven fabrics to response the consumers' needs; to suit all genders and different levels of income; and to be able to compete in a free market. 


\section{Research Objectives}

(1) To develop product prototypes from local woven fabrics in Pitsanulok province

(2) To compare the quality of fashion and bags based on the standardized criteria of community products from different groups of consumers according to genders and levels of income

(3) To present prototype products from local woven fabrics in Pitsanulok province

\section{Research Hypothesis}

The differences in genders and levels of income affect the differences in standardized criteria of the community products.

\section{Research Framework}

\subsection{Variables in the Study}

Independent variables: designed outfits and bags

Dependent variables: opinions of consumers towards quality and designed outfits and bags varied by genders and levels of income

\subsection{Population and Samplings}

Population: consumers who purchase the designed products from local woven fabrics at the local product distributing shops; 100 consumers a week

Samplings: 67 working people interested in the products in Pitsanulok province; using an accidental random selection

\subsection{Data Analysis}

Statistics methods used: descriptive analysis, average $(\overline{\mathrm{X}})$, standard deviation (S.D.); Hypothesis examined by test independent and One-Way ANOVA Assessment scales ranked at 4: 4= Very good, 3= Good, 2= Adequate, and $1=$ Need improvement

\section{Data Collection Procedure}

The researcher integrated the instruction of the Woven Fabrics design and fashion design course of the department Arts and Design at the faculty of Architecture of Nareasuan University. There were 12 students enrolling in this course. The students were to be at the scene to study how the fabrics were made. Then, the students were assigned to design and pattern the outfits and the bags. The students developed prototypes which were believed that the design would add the values to the products. Finally, the community used the design and pattern proposed as prototypes and produces their own products sold at the designated shops.

\section{Terms and Definitions in the Research Study}

Woven fabric product refers to the products made with handmade synthetic silk; the products made neatly from fine materials with fantastic patterns; the materials made solely in Pitsanulok province.

Quality of fashion and bags refers to general features which include:

1. Neatness- the neatness of the products should be outstanding, and no defect should be found.

2. Usefulness- the product should be practical.

3. Materials and manufacturing process

4. Marketing possibility and career promotion

5. Fineness, beauty, durability and appropriateness

\section{Research Conclusion}

According to an in-depth study of the Thai woven community enterprise group at Ban Krang Taa Wau in Muang District of Phitsanulok Province, Thailand, it was found that there were twelve members in the group and the group was led by Mr. Jareoy Deeleaw.The majority of the members were farmers. The researcher would like to present the research study in the o three main aspects which include: 1) the result of the prototype development from the local woven fabrics in Pitsanulok province 2) the result of the comparison of the consumers' opinions towards the quality of fashion and designs in mean scores and standard deviation scores according to features, genders, and levels of income 3) the product prototypes initiated by local woven fabrics in Pitsanulok province.

The analysis showed that the general features of the products were that the products were colorful; they came in 
many patterns including small and large plaid, twill, and chintz. Simple patterns of outfits and bags were made. The group would buy synthetic silk thread from factories to weave in the community. The principals of local woven fabrics applied the simple principal in weaving fabrics. The simple weaving is created with two interlaced sets of thread that form a grid-like pattern. One interlace was called "warp ikat" while the second one was called "weft ikat". Both sets of thread could be of the same or different colors. Moreover, the techniques of silver braid or gold braid could be integrated to offer a shine to the materials.

\section{The process of Weaving}

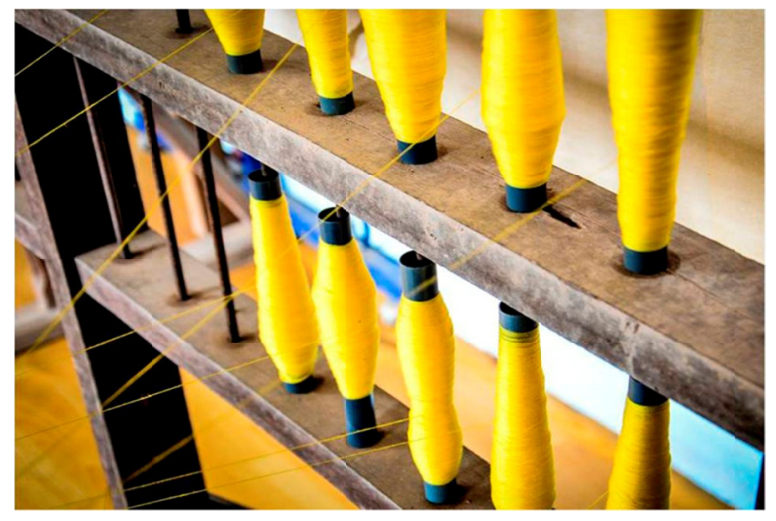

Figure 1. Thread cores for weaving

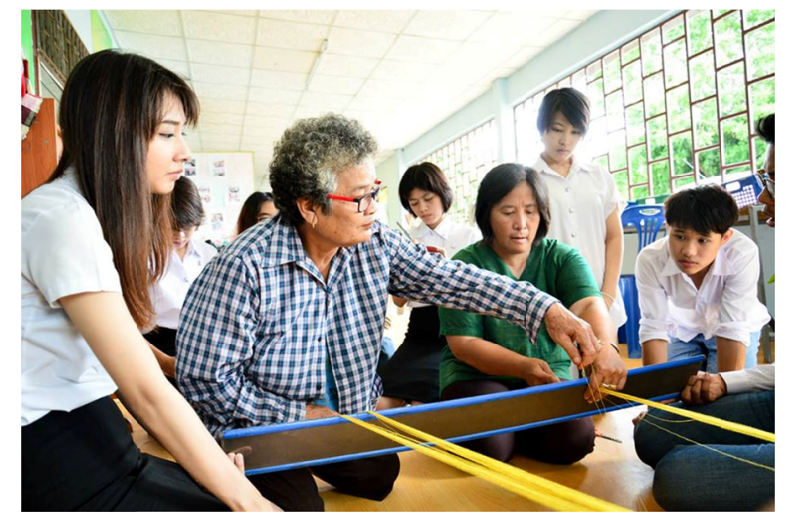

Figure 2. Combing threads; to fill 2 lines of thread at a time preventing thread from disheveling

1. Put main thread onto the warp ikat cores and needle each line of thread into the heddle and comb. Then pull all warp ikats onto the other side of the core. Adjust appropriately. Finally, pull the thread into the heddle and it will be used as weft ikat.

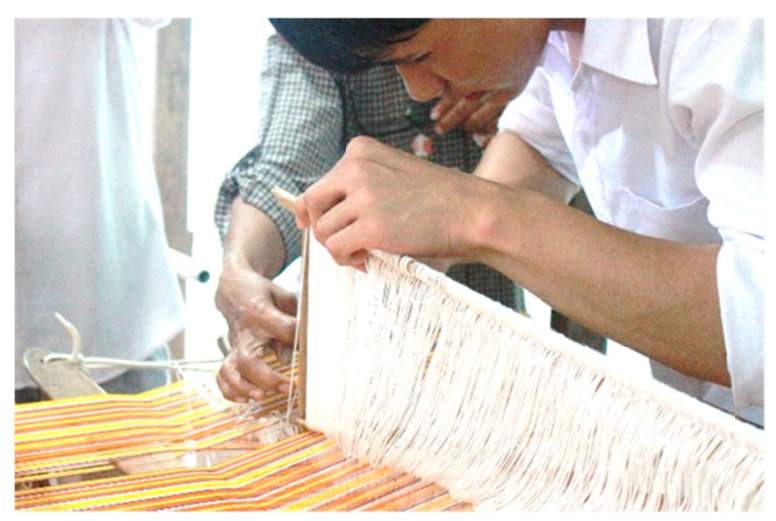

Figure 3. Connecting thread to loom

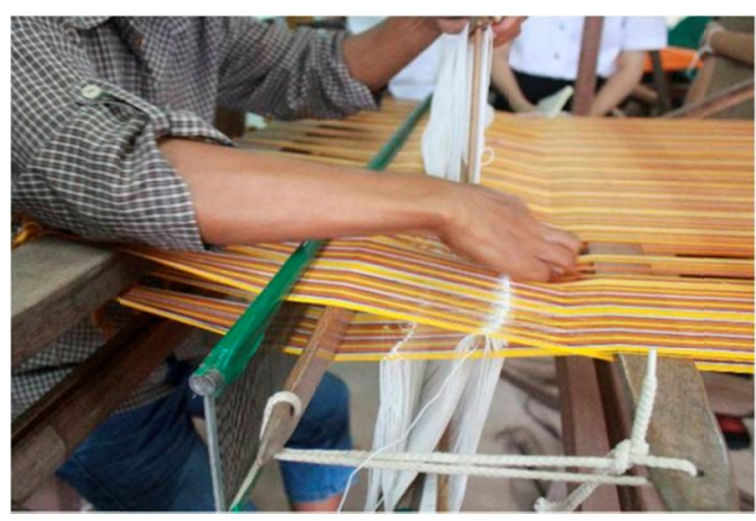

Figure 4. Alternating heddle 1 and heddle 2 to launch the shuttle creating warps

2. First, press on heddle to separate warp ikat set 1 and to create space. Then, simple insert warp ikat heddle alternatively between warp ikat set 1 and set 2 .

3. Filming technique - to hit the teeth of the comb when inserting weft ikat back; the weft ikat thread sticking together and tightening the fabric. 


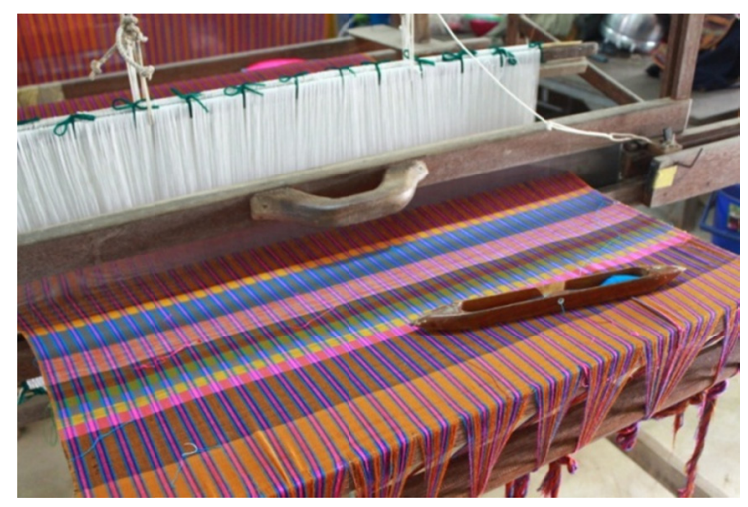

Figure 5. Plaid pattern with many colors; showing heddle with warping ikat

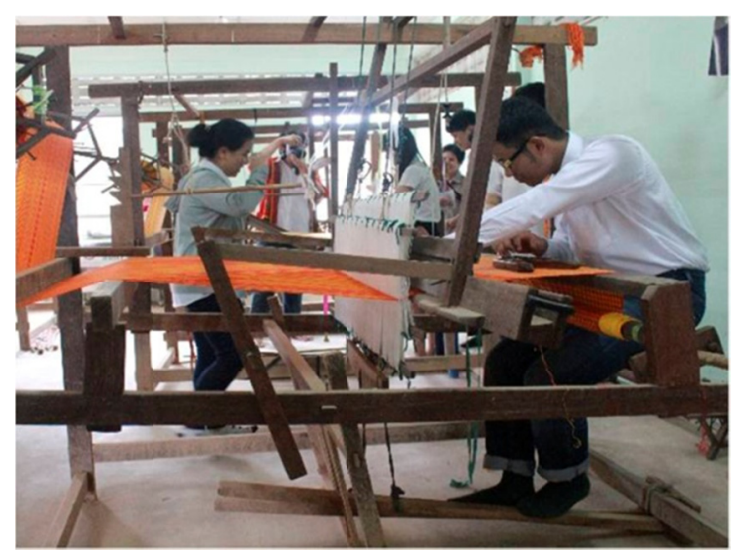

Figure 7. 2-heddle weaving loom. When producing a certain yard, the weaver should roll the farbic or keep it

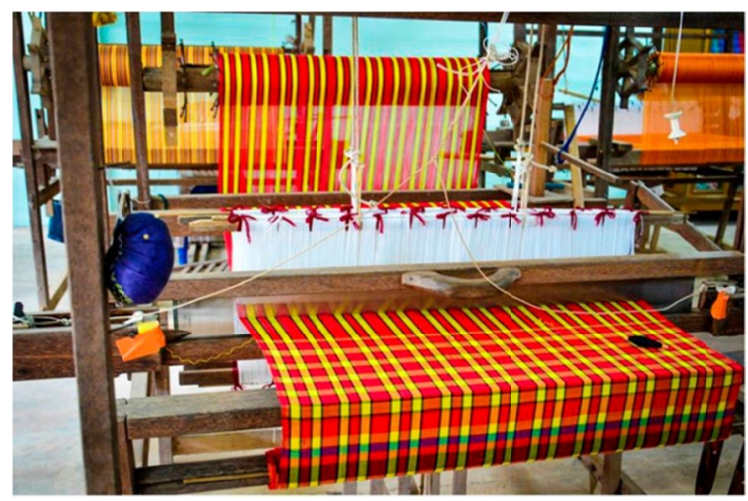

Figure 6. showing weaving a sheet of plaid pattern with different color threads; with tiny or big grids as designed

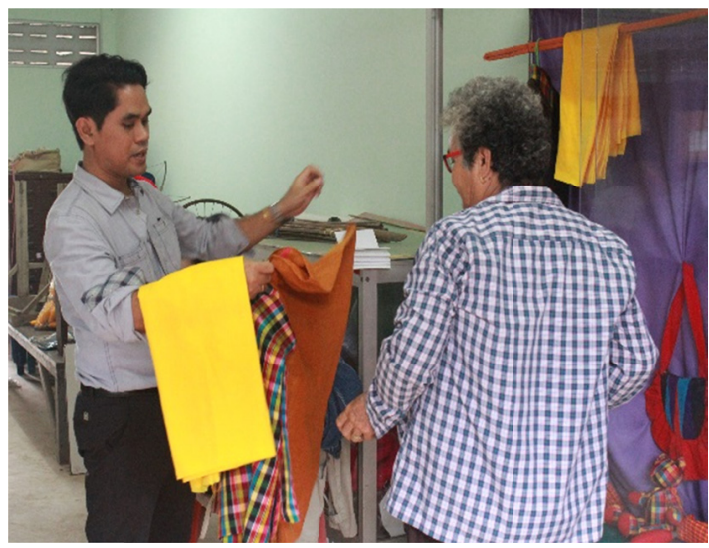

Figure 8. The final product of Community Enterprise Group in Phitsanulok; available in the community and made to order of the consumers

4. Rolling and storing the fabric. When producing a certain yard, the weaver should store the finished yard onto the core to loosen the warp ikat and adjust the fabrics appropriately.

The target consumers of this community enterprise group in Phitsanulok are the community inhabitants and the tourists who usually buy pieces of fabrics for souvenirs. Besides, other marketing channels are designated stores in the community and seasonal fairs. The community enterprise group is also welcome special orders to response to consumers' needs. The orders include fashion design, clothes with different patterns, and teenagers' bags. The product line which the group can develop is the fabric houseware. There have been several suggestions consisting of a variety of items and patterns, reasonable prices which suit the target consumers' purchasing power, and lastly the product promotions via seasonal fairs and events to make the products be known in the community and beyond. 


\section{Diagram 1 the process of fashion design}

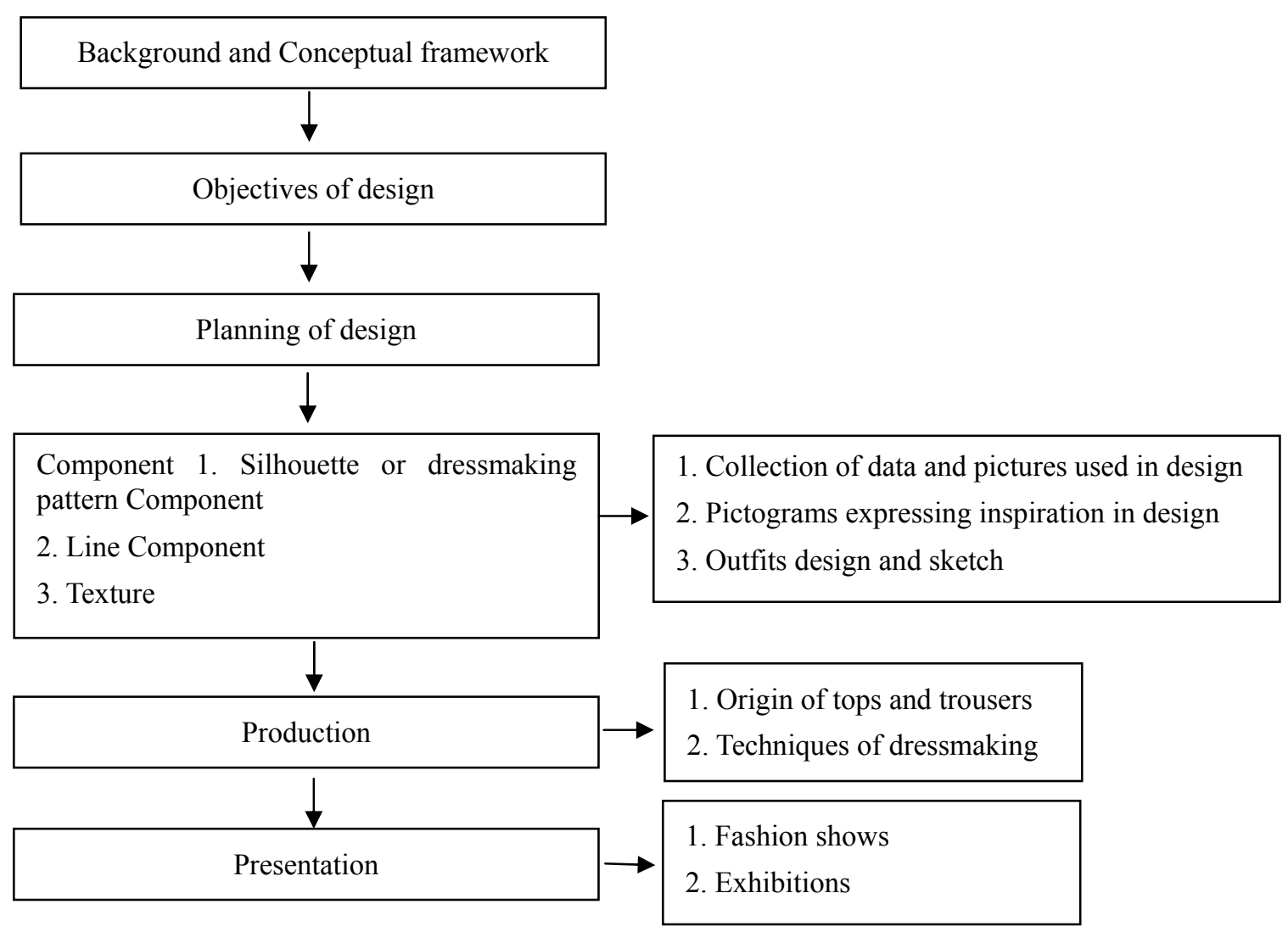

\section{The process in details}

The designers have to search for the inspiration, background and conceptual framework in design. This is to identify the objectives; for example, the designers need to think of the direction of the fashion; the designers need to consider the needs of the consumers. Later in the process, the planning and design processes involve. The designers finish with the sketch pattern after studying the top and trousers pattern including all cutting and stitching techniques. The final products include structure design and decorative design. All artistic elements also include lines, shapes, colors, knowledge about fabric and threads, a good match of pattern and material.

The overall manufacturing processes are as follows:

\section{Finding inspiration process}

This step involves the collection of data and the analysis of data to investigate the possibility in fashion design and to frame the main work.

\section{Collecting and Analyzing Process}

This step includes the development of sketch, pattern design, and delicate techniques on the fabrics and dressmaking.

\section{Designing Process}

This step includes the marking of the design process to make the idea concrete.

\section{Prototyping Process}

This step aims at communication.

\section{Finishing and Final Process}

This step includes a final touch and the completeness.

The followings are the examples of fashion design and bags. These products are made of woven fabrics from the community designated in this research project. There are 5 fashion bags and 8 attires. 


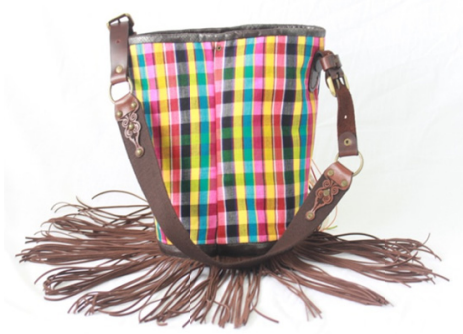

Figure 9. Bucket Bag- a bucket like bag decorated with leather strap and its bottom

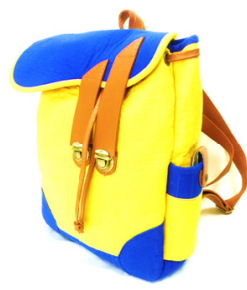

Figure 11. Backpack - a type of bag which you usually carry on your back when you are travelling

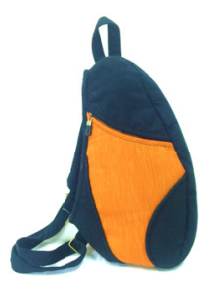

Figure 13. Fanny Bag or Hip/Waist Bag- a small bag fixed to a long strap which you fasten around your waist, and which is used for carrying money, keys, etc.

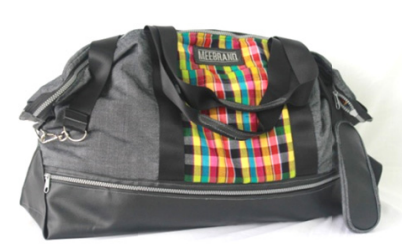

Figure 10. Duffle Bag a cylinder-like bag. It is roomy and soft. It is good for travelers and weekenders. This type of bag is also called a weekend bag

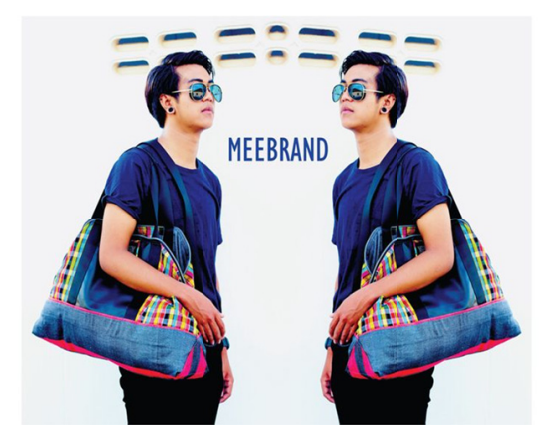

Figure 12. Duffle Bag- suitable for male teenagers. The material is plaid woven fabric of Community Enterprise Group

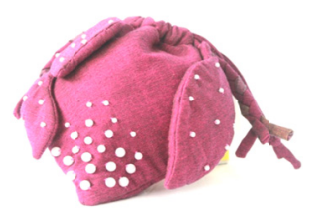

Figure 14.Wristlet- designed to fasten around your wrist; decorated with white bead 


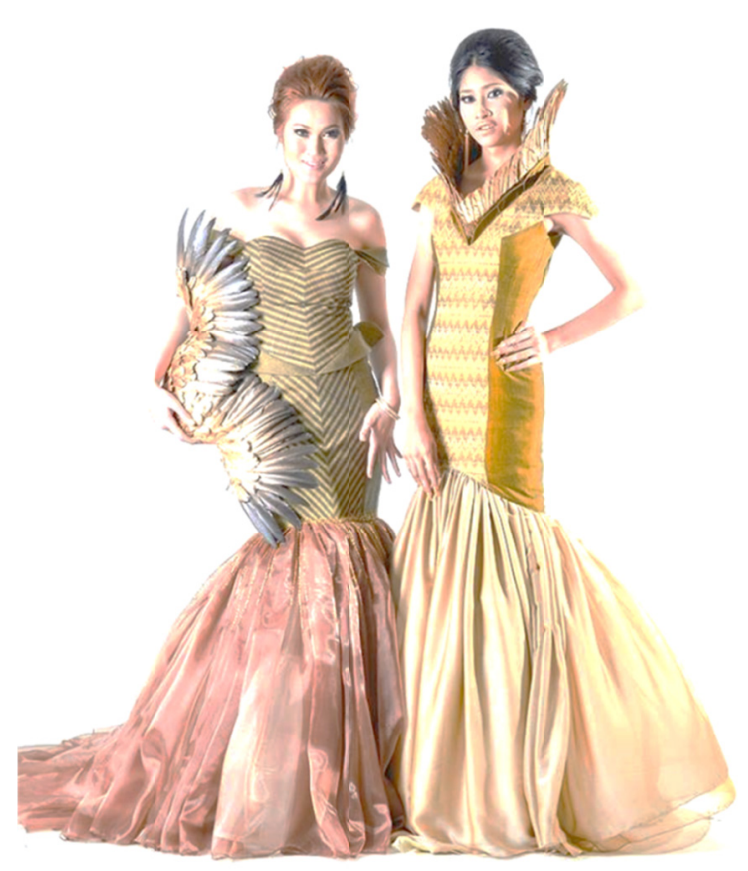

Figure 15. Evening gowns inspired by GRIFFIN (Lion and Eagle)

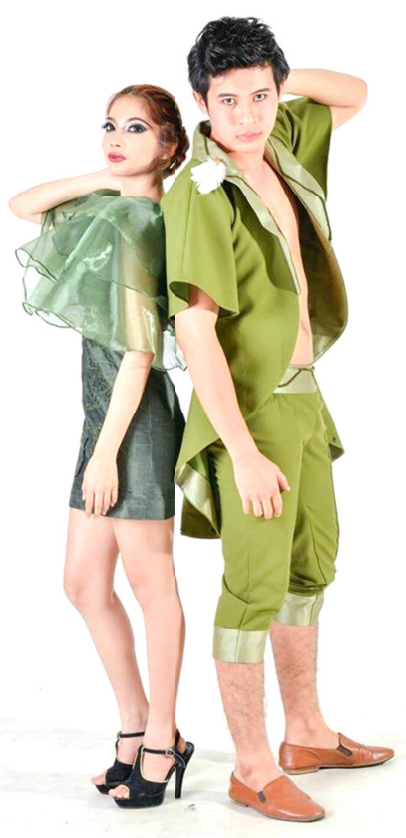

Figure 17. Lady and gentlemen outfits inspired by CAPRICORNUS (sea goat)

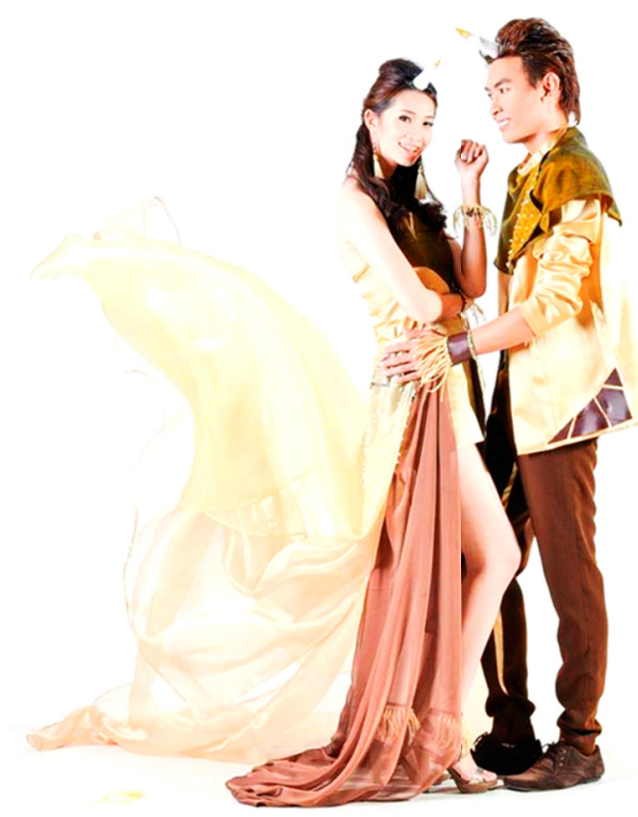

Figure 16. Lady and gentleman attires inspired by UNICORN (an imaginary white creature like a horse with a single horn growing from the front of its head.

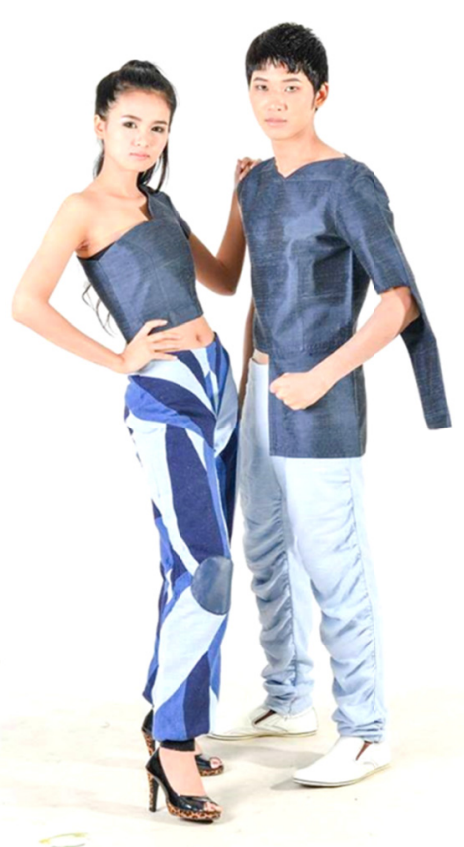

Figure 18. Lady and gentlemen outfits inspired by ANUBIS (robust and wearing a canine mask)

The Unicorn Capricornus and Anubis designs draw signature characteristics of each type of animals to design attires. The fabrics used are woven fabrics from the enterprise community and chiffon fabric, a very thin, almost transparent cloth of silk or nylon. The colors are brown, ivory, and green. Later, the beads and embroidery floss 
are used to decorate the attires. Moreover, bird feathers are used to decorate the collars to make the attires striking.

Table 1 . The result in the quality of fashion dresses from 67 consumers by genders

\begin{tabular}{|c|c|c|c|c|c|c|c|c|}
\hline \multirow{2}{*}{ Criteria } & \multicolumn{3}{|c|}{ Males $(n=19)$} & \multicolumn{3}{|c|}{ Females $(\mathrm{n}=48)$} & \multirow{2}{*}{$\mathrm{t}$} & \multirow{2}{*}{ sig } \\
\hline & $\overline{\mathrm{X}}$ & S.D & description & $\bar{X}$ & S.D & description & & \\
\hline \multicolumn{9}{|l|}{ General characteristics } \\
\hline $\begin{array}{l}\text { 1. neatness-the neatness of the products } \\
\text { should be outstanding, and no defect } \\
\text { should be found. }\end{array}$ & 3.26 & 0.73 & good & 3.41 & 0.49 & good & .839 & .410 \\
\hline 2. Practicality & 3.47 & 0.51 & good & 3.37 & 0.60 & good & .673 & .505 \\
\hline 3. materials and manufacturing process & 3.10 & 0.56 & good & 3.22 & 0.62 & good & .782 & .439 \\
\hline $\begin{array}{l}\text { 4. marketing possibility and career } \\
\text { promotion }\end{array}$ & 3.31 & 0.58 & good & 3.41 & 0.61 & good & .629 & .533 \\
\hline Other components (if any) & & & & & & & & \\
\hline $\begin{array}{l}\text { 5. fineness, beauty, durability and } \\
\text { appropriateness }\end{array}$ & 3.36 & 0.76 & good & 3.33 & 0.69 & good & .174 & .863 \\
\hline
\end{tabular}

Table 2. The comparison of the mean and standard deviation of the opinion of the consumers with different levels of income towards fashion design

\begin{tabular}{|c|c|c|c|c|c|c|c|c|c|c|c|c|}
\hline \multirow[t]{2}{*}{ Criteria } & \multicolumn{2}{|c|}{ Below } & \multicolumn{2}{|c|}{$\begin{array}{c}10,000- \\
14,499\end{array}$} & \multicolumn{2}{|c|}{$\begin{array}{c}15,000- \\
19,999\end{array}$} & \multicolumn{2}{|c|}{$\begin{array}{l}20,000- \\
29,999\end{array}$} & \multicolumn{2}{|c|}{$\begin{array}{l}30,000- \\
49,999\end{array}$} & \multicolumn{2}{|c|}{$\begin{array}{c}50,000 \\
\text { and over }\end{array}$} \\
\hline & $\overline{\mathrm{X}}$ & S.D & $\bar{X}$ & S.D & $\bar{X}$ & S.D & $\overline{\mathrm{X}}$ & S.D & $\overline{\mathrm{X}}$ & S.D & $\overline{\mathrm{X}}$ & S.D \\
\hline \multicolumn{13}{|l|}{$\underline{\text { General characteristics }}$} \\
\hline $\begin{array}{l}\text { 1. neatness- the neatness of the } \\
\text { products should be } \\
\text { outstanding, and no defect } \\
\text { should be found. }\end{array}$ & 3.57 & 0.53 & 3.58 & 0.50 & 3.07 & 0.61 & 3.33 & 0.57 & 3.40 & 0.54 & 3.33 & 0.57 \\
\hline 2. Practicality & 3.17 & 0.48 & 3.47 & 0.51 & 3.21 & 0.42 & 3.19 & 0.67 & 4.00 & 0.00 & 3.66 & 0.57 \\
\hline $\begin{array}{l}\text { 3. materials and } \\
\text { manufacturing process }\end{array}$ & 3.00 & 0.81 & 3.23 & 0.56 & 3.07 & 0.47 & 3.28 & 0.64 & 3.40 & 0.54 & 3.00 & 1.00 \\
\hline $\begin{array}{l}\text { 4. marketing possibility and } \\
\text { career promotion }\end{array}$ & 3.40 & 0.53 & 3.35 & 0.49 & 3.28 & 0.72 & 3.42 & 0.67 & 3.60 & 0.54 & 3.33 & 0.57 \\
\hline \multicolumn{13}{|l|}{ Other components (if any) } \\
\hline $\begin{array}{l}\text { 5. fineness, beauty, durability } \\
\text { and appropriateness }\end{array}$ & 3.57 & 0.53 & 3.58 & 0.50 & 3.07 & 0.73 & 3.09 & 0.83 & 4.00 & 0.00 & 3.33 & 0.57 \\
\hline
\end{tabular}

Table 2 represents the level of quality in fashion design according to the opinion of the consumers with different levels of income towards fashion design. It was found that consumers with an income of below Baht. 10,000 ranked the neatness of the products first while consumers with an income of above Baht. 50,000 focused on the practicality of the products. Moreover, consumers with an income between Baht. 30,000-49,000 ranked the neatness of the products; fineness, beauty, durability and appropriateness; and practicality the top three important qualities. 
Table 3. The analysis of variance of the overall quality levels according to levels of income

\begin{tabular}{ccccccc}
\hline Criteria & $\begin{array}{c}\text { Source of } \\
\text { variation }\end{array}$ & SS & df & MS & F & Sig. \\
\hline $\begin{array}{c}\text { General characteristics } \\
\text { 1. neatness-the neatness of the } \\
\text { products should be outstanding, and } \\
\text { no defect should be found. }\end{array}$ & Between Groups & 2.378 & 5 & .476 & 1.504 & .202 \\
Within Groups & 19.294 & 61 & .316 & & \\
2. Practicality & Total & 21.672 & 66 & & & \\
& Between Groups & 4.194 & 5 & .839 & $2.854^{*}$ & .022 \\
& Within Groups & 17.926 & 61 & .294 & & \\
3. materials and manufacturing & Total & 22.119 & 66 & & & \\
process & Between Groups & 1.005 & 5 & .201 & .522 & .759 \\
& Within Groups & 23.473 & 61 & .385 & & \\
4. marketing possibility and career & Total & 24.478 & 66 & & & \\
promotion & Between Groups & .447 & 5 & .089 & .232 & .947 \\
& Within Groups & 23.463 & 61 & .385 & & \\
Other components (if any) & Total & 23.910 & 66 & & & \\
5. fineness, beauty, durability and & Between Groups & 5.868 & 5 & 1.174 & $2.628^{*}$ & .032 \\
appropriateness & Within Groups & 27.237 & 61 & .447 & & \\
\hline
\end{tabular}

$* \mathrm{P}<0.05$ significantly different at the level of 0.05

Table 3 shows the satisfaction of the consumers towards the overall quality according to their different levels of the income. There were no significant differences found except for the practicality aspect. That is to say the consumers with 10,000-14,449, 30,000-49,999, and over 50,000 were different. The formers focused on neatness while the latters focused on the fineness, beauty, durability and appropriateness.

\section{Discussion}

The results of the development of fashion design from woven fabrics of community enterprise group in Phitsanulok province, Thailand were five styles of bags and eight sets of outfits. The bags made from the woven fabrics of the community enterprise vary from Bucket Bag, Duffle Bag, Backpack, and Fanny Bag to Wristlet. While the outfits which were inspired from the mythology range from Griffin Unicorn, Capricornus to Anubis. All of the products were designed and made properly reaching the standard criteria. According to the assessment from the consumers, it was found that the overall scale is good. The design product and fabric colour selection in the collection of researcher were corresponding with the color experts who are influenced in color design and trend in fashion world. The 10 colors trend were revealed and expected to be popular in fashion for spring and summer in 2016. For example, Peach Echo as orange trend color always a popular color in fashion industry trough out every seasons. This color give the sence of warm and friendly feeling. Iced coffee as brown trend color is the natural sence give us a soft and gentle feeling while Snorkel Blue is the trend color of energetic and cheerfully sence and also relaxing and independent feeling.

As regards the design of the outfits, Wongsighathong (2004) explained that in designing the outfits, there were both the constraints in the esthetic appeal and practicality aspect. The decent one should offer the wearer a feeling of comfort and workability. Chapoorum (2005) studied the achievement of the one tumboon (subdistrict), one product policy; a case study of silk fabric group in Na Pho sub-district and Don Kok sub-district. The results of the study were that 1) the gathering of the silk fabric group in Na Pho sub-district was longer, bigger and more powerful than that of Don Kok sub-district; 2) as regards the achievement, the products of Na Pho sub-district group were selected OTOP Product Champion with a five-star guarantee. This was because the products reached all criteria identified by the Thai government. The criteria included the legend of the group, the legend of the products, manufacturing processes, marketing strategies, the processing of the products, and the sustainability of the group. This also involved the business administration and the capital. This group was self-sufficient while Don Kok sub-district group, OTOP Product Champion with three stars, was not 
self-sufficient. Its main product was silk fabric. The Don Kok group still relied on the government subsidiary. Moreover, its production line could not respond to the demand of the consumers in time. The group needed to improve only on the production but also the marketing strategies and the processing. Boonla (2003) studied the marketing development for silk products. The objectives were to study the problems and obstacles important to the development in many aspects. This included consumer behaviors. The results were that in Bangkok metropolitan area, there were four main the problems and obstacles found. This included 1) the limitations of silk fabric products themselves; 2) the attitudes of consumers towards the brand image and reputation; 3 ) source of production; 4) channel of distribution; and 5) the ability of competition. Sriboonsom (1991) studied the effects of the economy and society on weaving occupation in Hnong Keun Chang Village, Tah Song Kon sub-district, Muang District in Mahasarakam province. The results were that 1) Hnong Keun Chang Village has been settled for about 300 years. The population believed in Buddhism and spoke North Eastern dialect. The main occupation is agriculture and part-time self-employment was weaving; 2) the government bureau and some private sections helped with the distribution after the group had settled for a long while; 3) the development of the weaving market led to a widespread access to both domestic and international weaving markets; 4) the villages gained more income from weaving; 5) the changes in life style resulted in the villagers' economy. That is to say they had more opportunities in creating jobs; they had chances to make more money. Thus, they had purchasing power. Moreover, there was less number of villagers migrating to the urban for jobs. All in all, the weaving group brought about fame, income, facilities and at the same time the more money villagers could make, the lower unemployment rate revealed. Surasieng et all (2004) studied the needs of labor skills for Thai fabric manufacturing and Thai material used products: a case study in Nan province. It was found that Thai fabrics were unique. To enhance the ability to compete in the global market, it was necessary that the weavers must be skillful and the clothes themselves must have a variety in their patterns and practicality. The fabrics from Nan province were recruited in this case study. This case exemplified manufacturing, distributing, change management as well as skilled weavers which were required for the prosperous future of this market, which made up to Baht 60 million each year.

In the past, the gathering of weaving group was found in the provinces where support was lack and knowledge management was unsystematic. The knowledge or information was transferred in the family or in the group orally. The majority of the products were copies and the marketing plan was not systematic. The distribution of the products was made through the middle man, considering an old-fashioned marketing method. The price was defined by the middle man, neither by the practicality nor the use of them. The exhibition was not well received. However, nowadays the marketing strategies for Thai fabrics have been modified to suit the need and community changes. There have been many distributing centers and selling points in many provinces.

To design fashions for competition, the makers need to plan well and forecast the possibility of the market. The consumers will be of the same group, working people and tourists. However, we need to be ready for the changes. We need to provide unique products with good quality and variety. The neatness, creativity, and practicality should go hand in hand. In addition, the government and private sectors should play roles in promoting the products, enhancing skills of the weavers, and transferring knowledge of such a kind from generation to generation systematically. The future competitors are still domestic competitors. The handicraft industry community in Thailand still has rooms for improvement and it is essential that all parties join hands and collaborate in strengthening Thai fabrics.

\section{Suggestions}

Thai fabrics should be promoted and artistically developed to be able to compete in a variety of markets ranging from the domestic to the international ones. However, according to the results of the study, many problems were found as follows:

1. The handicrafts in many areas have been neglected; they were not been promoted and distributed properly. The information technology system should be incorporated to research and development.

2. There have not been enough motivations both from the group and the outsiders; as a consequence, a contest or an exhibition of design and production would be another way to publicize the products as well as the skills.

3. The income from the weaving job is not stable and foreseeable. This problem led to a change in occupation. Many people turned to be labors. Hence, an effective distribution channel and promotional selling points would increase sales drive and definitely bring more money to the villagers and the weavers.

4. When the neatness and quality are inconsistent, the quality of the fabrics as well as the skills of the weavers would decrease. There is no advancement in the field. Therefore, there should be workshops or idea sharing forum where the technology, science, and arts are discusses and transferred to the community. 
5. As for time issue, a skilled worker usually takes a lot of time to finish a piece of fabric; the fabric is expensive. Price is also one factor deterring consumers from buying hand woven fabrics. Therefore, we should help promote them as well as offer them a workshop on foundation design.

6. Knowledge transfer is limited in a certain groups of people or family. Thus, the community should organize a place where Thai fabrics can be kept and displayed. People, villagers, and weavers should gather here and transfer knowledge. A local wisdom or local expert should also play roles in transferring knowledge. The knowledge in weaving and Thai fabrics will be shared and extended.

\section{References}

Boonla, M. (2003). Development of the market for silk products. Thailand. Master thesis (Business Administration) Kasem Bundit University.

Chapooram, N. (2005). Achievement of One Tambon One Product Policy: A Case Study of silk and Don Kok Po Na Na Pho District, Buriram province (Master thesis: Public Administration). Kasem Bundit University.

Fashion Color Report Spring. (2016). New York Fashion Week September 10 - 17, 2015. The Pantone Color Institute. Retrieved from http://www.pantone.com/press-release-pantonecolor-institute-announces-spring2016-fashion-color-report

Singthongwon, P. (2004). History of Costume. Bangkok, Infor media international.

Sriboomsaom, S. (1981). Effects of the economic and social fabric weavers. Dam Nong Chang Ta Khon Muang Maha Sarakham province. Master thesis (Thailand case study - focused on social sciences). Maha Sarakham University.

Surasiangsang, S. (2004). Demand for skilled labor in the production of fabric and composite fabrics products, Thailand: A Case Study of Nan province. Faculty of Commerce and Accountancy. Chulalongkorn University.

\section{Copyrights}

Copyright for this article is retained by the author(s), with first publication rights granted to the journal.

This is an open-access article distributed under the terms and conditions of the Creative Commons Attribution license (http://creativecommons.org/licenses/by/3.0/). 